\title{
DECISIONS
}

\section{Gender dysphoria in a 39-year-old man}

\author{
Jamie Feldman MD PhD, Katherine Spencer PhD
}

\begin{abstract}
A 39-year-old married man with a history of depression presents to his primary physician requesting estrogen. He explains that he has felt "more like a girl" since his early teen years and states that he can no longer tolerate living this way. A physical examination shows mild gynecomastia and diminished body hair. The patient declines a genital examination.
\end{abstract}

\section{What diagnoses should be considered?}

The primary diagnoses to consider are gender dysphoria, transvestic disorder (formerly known as transvestic festishism) and depression with psychosis.

"Transgender" is an adjective used to describe a diverse group of people who cross or transcend culturally defined categories of gender. ${ }^{1}$ Transgender people may or may not have gender dysphoria. Gender dysphoria refers to distress caused by a discrepancy between a person's gender identity and the physical or genital sex the person was assigned at birth. ${ }^{1}$ People with persistent gender dysphoria may meet criteria for a formal mental health diagnosis that benefits from treatment. ${ }^{1}$ Formerly known as gender identity disorder, this diagnosis is now designated gender dysphoria in the Diagnostic Statistical Manual of Mental Disorders, fifth edition (DSM-5), and is characterized by a marked and durable ( $\geq 6 \mathrm{mo}$ ) incongruence between one's experienced or expressed gender and one's assigned gender. It is associated with clinically significant distress or impairment in social, occupational or other areas of functioning, or with a substantially increased risk of suffering, distress or disability.

Health care providers should consider transvestic disorder and depression with psychosis if the patient reports gender dysphoria that is intermittent and paired with sexual arousal, shows impaired reality testing or has active psychosis. Disorders of sexual development (e.g., congenital adrenal hyperplasia, androgen insensitivity syndrome), also known as intersex conditions, rarely present with gender dysphoria, ${ }^{2}$ although chronic symptoms may later develop in some patients. ${ }^{1}$

\section{How should this patient be assessed?}

Patients who are questioning their gender may be unsure how to express their concerns or may present with confusion about their sexual orientation. Sensitive questioning is needed to create an environment conducive to discussing concerns relating to gender. Because patients can be appropriately fearful of negative consequences should they disclose their gender dysphoria, ${ }^{3}$ they may present initially with depression or anxiety. Transgender people, in dealing with social stigma, can be at risk for higher rates of suicidal ideation stemming from societal, peer or family rejection. ${ }^{4}$

Patients with gender dysphoria will often seek hormone therapy to relieve their symptoms. The physical changes in this patient, for example, are more likely due to the use of feminizing hormones than to an underlying pathology. Transgender people may self-medicate with nonprescribed hormones, often procured over the Internet, because of fear of the medical system or lack of access to health care providers well-versed in this condition. ${ }^{3}$ A history of the type and duration of hormone use, a cardiovascular and pulmonary examination and laboratory investigations for potential adverse effects of feminizing hormones would be appropriate in this setting (for resources, see Appendix 1, available at www.cmaj.ca/lookup/suppl/doi:10 .1503/cmaj.130450/-/DC1).

As noted in multiple qualitative studies, patients with gender dysphoria are often uncomfortable with their bodies, avoiding genital examinations or health care altogether. ${ }^{3,5}$ Physicians should assess basic health care needs, including physical examinations and laboratory investigations as indicated. Genital and breast examinations should be avoided if possible, because patients may feel highly distressed about their secondary sexual characteristics. It is important, however, to assess for potential self-harm to the genitals or breasts. ${ }^{6.7}$

\section{What further assessment would be needed before treatment is considered?}

Expert consensus recommends that health care providers determine the persistence and degree of gender dysphoria by establishing with patients
Competing interests: None declared.

This article has been peer reviewed.

Correspondence to: Jamie Feldman, feldm010@umn.edu

CMAJ 2014. DOI:10.1503 /cmaj.130450 
their goals for feminization or masculinization, beginning with when patients report the desire to live as a different gender. ${ }^{1}$ Assessing the effects of the onset of puberty can inform practitioners about the intensity of gender dysphoria as secondary sexual characteristics developed.

The World Professional Association for Transgender Health (WPATH) Standards of Care, version 7 , provides a framework for the treatment of gender dysphoria. ${ }^{1}$ The quality of evidence behind this framework ranges from low to moderate and is drawn from expert consensus, as well as large retrospective and small prospective studies, depending on the specific topic. ${ }^{1}$ The criteria require a psychosocial assessment by a mental health or primary care professional trained to assess behavioural health and gender dysphoria before hormone therapy is started (Box 1). This assessment should diagnose persistent gender dysphoria, stabilize any cooccurring mental health concerns and assist patients in learning about their options for hormone therapy. ${ }^{1}$ Once a psychosocial assessment is complete, a medical evaluation should ensure that the patient is informed as to the risks of hormone therapy, and that any medical conditions are stable before starting therapy. Resources for psychosocial and medical assessment are listed in Appendix 1.

Hormone therapy to induce feminizing or masculinizing changes is a medically necessary intervention for many transgender patients. Mental health professionals, including primary care providers, should assist patients with making thoughtful decisions about communicating with partners and family members about their gender identity and treatment decisions.

Depression and anxiety often can be substantially decreased through accurate diagnosis and treatment of the underlying gender dysphoria. ${ }^{8}$

\section{Should this patient be referred?}

Primary care providers can make an initial assessment of gender dysphoria, the degree of distress and use of self-medication with hormones. If the patient desires hormone therapy, psychosocial and

\section{Box 1: World Professional Association for Transgender Health} Standards of Care, version 7, criteria for hormone therapy ${ }^{2}$

Hormone therapy can be started after a psychosocial assessment has been conducted and informed consent has been obtained. A referral for hormone therapy is required from the mental health professional who has performed the psychosocial assessment, unless the assessment was done by a medical provider who is also qualified in this area.

- Persistent, well-documented gender dysphoria;

- Capacity to make a fully informed decision and to give consent for treatment;

- Age of majority;

- If important medical or mental concerns are present, they must be reasonably well-controlled. medical assessments, including the capacity to make a fully informed decision and give consent for treatment, should be performed by a trained health care provider, which may or may not necessitate referral. Primary care providers can provide effective transgender hormone therapies in the setting of comprehensive health care (Appendix 1). ${ }^{1}$

If the primary care provider is unable to provide hormone therapy, referral to an experienced clinician, whether in primary care or endocrinology, would be appropriate. Although urban centres in some provinces have clinics known for providing care for transgender patients, access to psychosocial support, hormones and surgical services is variable by province, may require considerable travel and may not be covered by public health insurance. The Canadian Professional Association for Transgender Health (CPATH) is a valuable resource for patients and health care providers (Appendix 1).

\section{Case revisited}

The patient acknowledges intermittent use of estrogen taken orally, which was purchased over the Internet. The patient agrees to discontinue its use and be referred to a therapist experienced in gender dysphoria.

\section{References}

1. Coleman E, Bockting W, Botzer M, et al. Standards of care for the health of transsexual, transgender, and gender-nonconforming people, version 7. Int J Transgender 2012;13:165-232.

2. Meyer-Bahlburg HFL. Variants of gender differentiation in somatic disorders of sex development: recommendations for version 7 of the World Professional Association for Transgender Health's standards of care. Int J Transgende 2009;11:226-37.

3. Grant JM, Mottet LA, Tanis J, et al. National transgender discrimination survey report on health and health care. Washington (DC): National Center for Transgender Equality and National Gay and Lesbian Task Force; 2010:1-23.

4. Nooshin Khobzi R, Bauer GR, Travers R, et al. Depression in male-to-female transgender Ontarians: results from the Trans PULSE Project. Can J Commun Ment Health 2011;30:113-33.

5. Feldman J. Preventive care of the transgendered patient: an evidence based approach. In: Ettner R, Monstrey S, Eyler E, editors. Principles of transgender medicine and surgery. Binghampton (NY): Haworth Press; 2006.

6. Bockting WO, Knudson G, Goldberg JM. Counseling and mental health care for transgender adults and loved ones. Int J Transgender 2006;9:35-82.

7. Xavier JM, Hitchcock D, Hollinshead S, et al. An overview of US trans health priorities: a report by the Eliminating Disparities Working Group: August 2004 update. Washington (DC): National Coalition for LGBT Health; 2004. Available: http://transequality.org/PDFs/HealthPriorities.pdf (accessed 2013 Sept. 17)

8. Gómez-Gil E, Zubiaurre-Elorza L, Esteva I, et al. Hormonetreated transsexuals report less social distress, anxiety and depression. Psychoneuroendocrinology 2012;37:662-70.

Affiliation: Department of Family Medicine and Community Health, Program in Human Sexuality, University of Minnesota, Minneapolis, Minn.

Contributors: Katherine Spencer contributed content related to alternative diagnoses and specific assessment of gender dysphoria and contributed substantially to the overall critical review of psychologically related material. Jamie Feldman was responsible for the conception, main content and writing and editing of the article. Both of the authors approved the final version of the article submitted for publication. 